\title{
IoT6 Project in a Nutshell
}

\author{
Sébastien Ziegler and Cedric Crettaz \\ Mandat International, Geneva, Switzerland \\ \{iot6, sziegler\} @mandint.org
}

\begin{abstract}
IoT6 aims at exploiting the potential of IPv6 and related standards to overcome current shortcomings and fragmentation of the Internet of Things. The main objectives of the project are to research, design and develop a highly scalable IPv6-based Service-Oriented Architecture to achieve interoperability, mobility, cloud computing integration and intelligence distribution among heterogeneous smart things components, applications and services.
\end{abstract}

Keywords: IoT, M2M, IPv6, CoAP, architecture, interoperability, building automation.

The Internet of Things is exponentially growing towards an ecosystem interconnecting tens of billions of smart things. Simultaneously, the Internet is facing a significant transformation by moving to a new Internet protocol: the Internet Protocol version 6 (IPv6), which is scaling up the Internet to an almost unlimited number of globally reachable addresses.

IoT6 [1] is a 3 years FP7 European research project on the Internet of Things that started in October 2011 and will finish in September 2014. It aims at researching and exploiting the potential of IPv6 and related standards (6LoWPAN [2], CoAP [3], etc.) to address current needs of the Internet of Things. Its main challenges and objectives are to research, design and develop a highly scalable IPv6-based Service-Oriented Architecture. Its potential will be researched by exploring innovative forms of interactions such as:

- Provide generic techniques and interfaces to bridge different technologies to ensure communication over IPv6

- Information and intelligence distribution, with concepts such as "smart routing", exploiting IPv6-related features to enable a distributed data transmission management between a high number of IoT components and services.

- Multi-protocol interoperability with and among heterogeneous devices using all kinds of IP and non-IP communication protocols.

- Device mobility and the role of mobile phones in providing ubiquitous access to smart things

- Cloud computing integration with a focus on Software as a Service (SaaS) interconnected with smart things. 
- IPv6 - Smart Things Information Services (STIS) innovative interactions, by exploring the potential of IPv6 to locate, identify and provide information on all kind of smart things.

The main outcomes of IoT6 will be recommendations on IPv6 features exploitation for the Internet of Things and an open and well-defined IPv6-based Service Oriented Architecture enabling interoperability, mobility, cloud computing and intelligence distribution among heterogeneous smart things components, applications and services, including with business processes management tools. It is exploring both horizontal (cross-domain) and vertical (IoT - cloud) integrations.
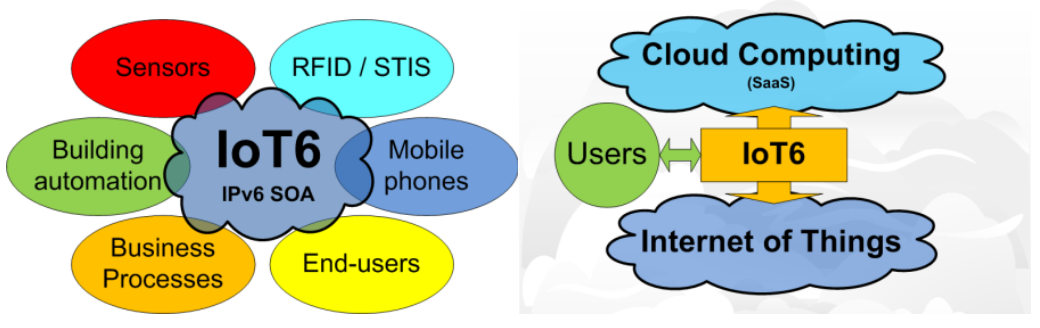

The project has already designed and developed most of its targeted IPv6-based IoT architecture taking the existing work done in ETSI M2M, IoT-A [5], and FIWARE [6] as the basis. The initial integration with sensors, building automation components, tags, mobile phones and software as a service has been demonstrated. The project has also developed an innovative lookup and discovery system, named "Digcovery" [7]. More detailed information is provided in the Chapter "IoT6 - Moving to an IPv6-based future IoT". Finally, the project has organized several events and workshops in cooperation with other European research projects in order to synergize efforts and align their visions on IPv6 exploitation for the future Internet of Things. IoT6 members have also been elected to chair the new IoT TC Subcommittee of IEEE Communication Society [8], giving Europe a leading role and responsibility.

Open Access. This article is distributed under the terms of the Creative Commons Attribution Noncommercial License which permits any noncommercial use, distribution, and reproduction in any medium, provided the original author(s) and source are credited.

\section{References}

1. IoT6, http: //www. iot6.eu

2. IPv6 over Low-Power Wireless Personal Area Networks (6LoWPANs), https: / / tools.ietf.org/html/rfc4919

3. Constrained Application Protocol (CoAP), draft-ietf-core-coap-11 (July 16, 2012), https: / /datatracker.ietf.org/doc/draft-ietf-core-coap/

4. ETSI M2M Communications, http: / / www.etsi .org/website/technologies/m2m.aspx 
5. Internet of Things Architecture, IoT-A, http://www. iot-a. eu

6. FI-WARE, http://www.fi-ppp.eu/about-us/projects/fi-ware/

7. Jara, A.J., Martinez-Julia, P., Skarmeta, A.F.: Light-weight multicast DNS and DNS-SD (lmDNS-SD): IPv6-based resource and service discovery for the Web of Things. In: International Workshop on Extending Seamlessly to the Internet of Things (2012)

8. IEEE Communications Society, SubCommitee on the Internet of Things, http://www. comsoc.org/about/committees/emerging 